\section{$\underset{\substack{\text { hommes } \\ \text { \& migrations }}}{ }$}

\section{Hommes \& migrations}

Revue française de référence sur les dynamiques

migratoires

$1304 \mid 2013$

Frontières

\title{
Romain Puértolas, L'Extraordinaire Voyage du fakir qui était resté coincé dans une armoire Ikéa,
}

Paris, Le Dilettante, 2013, 253 p., $19 €$.

\section{Mustapha Harzoune}

\section{(2) OpenEdition}

\section{Journals}

Édition électronique

URL : http://journals.openedition.org/hommesmigrations/2695

DOI : 10.4000/hommesmigrations.2695

ISSN : 2262-3353

Éditeur

Musée national de l'histoire de l'immigration

Édition imprimée

Date de publication : 1 octobre 2013

Pagination : 189

ISBN : 978-2-919040-24-7

ISSN : 1142-852X

Référence électronique

Mustapha Harzoune, « Romain Puértolas, L'Extraordinaire Voyage du fakir qui était resté coincé dans une armoire Ikéa, », Hommes \& migrations [En ligne], 1304 | 2013, mis en ligne le 20 mars 2014, consulté le 22 septembre 2020. URL : http://journals.openedition.org/hommesmigrations/2695 ; DOI : https:// doi.org/10.4000/hommesmigrations.2695

Ce document a été généré automatiquement le 22 septembre 2020.

Tous droits réservés 


\section{Romain Puértolas, L'Extraordinaire Voyage du fakir qui était resté coincé dans une armoire Ikéa,}

Paris, Le Dilettante, 2013, 253 p., $19 €$.

Mustapha Harzoune

\section{RÉFÉRENCE}

Romain Puértolas, L'Extraordinaire Voyage du fakir qui était resté coincé dans une armoire Ikéa, , Le Dilettante, 2013, 253 p., $19 €$.

1 Romain Puértolas est un nouveau venu dans la carrière. Ce Montpelliérain né au mitan de la décennie 1970 n'a cessé de vadrouiller entre la France, l'Angleterre et l'Espagne mais surtout professionnellement: DJ, compositeur-interprète, prof de langue, traducteur, steward, magicien (ce qui a son importance ici), il serait aujourd'hui lieutenant de police (ce qui est aussi important que ses tours de magie). L'Extraordinaire Voyage du fakir qui était resté coincé dans une armoire Ikea est un roman loufoque, invraisemblable, drôle, qui, avec humour et poésie, traite d'un sujet envahissant - en littérature ou à l'écran plus que sur nos frontières: l'immigration! Puértolas ne renouvelle pas le genre. Il y a peu, l'Algérien Salim Bachi, et ses Amours et aventures de Sindbad le Marin (Gallimard, 2010), nageait déjà dans les mêmes eaux. Une chose est sûre : Puértolas écrit avec originalité, tient son lecteur - toujours souriant - en haleine, ne pose pas en donneur de leçons, mais permet de (re)penser les questions de l'immigration et de porter un autre regard sur les migrants.

D'Inde à Paris en passant par un détour obligé par l'Angleterre, l'Espagne, l'Italie et la Libye, Ajatashatru Lavash Patel (je vous renvoie au livre pour les différentes prononciations), clandestin malgré lui, fakir de son état, débarqué dans un magasin Ikea pour se procurer le dernier modèle de lit à clous "Kisifrötsipik", découvre, en neuf jour, un monde de lui ignoré et sort de cette aventure totalement transformé. Ce roi de 
l'entourloupe apprend la générosité, l'empathie, l'amour. “Un migrant qui ne reste qu'un immigré est un migrant raté", disait Mohamed Dib. L'égoïste, le fourbe et mystificateur d'hier "allait s'affairer à devenir quelqu'un de bien", débordant "d'amour, de compassion et de fraternité". Son périple européen lui a ouvert les yeux sur ses semblables: "Les "beaux pays' étaient vraiment une boîte de chocolats pleine de surprises. Et la police n'était pas toujours le comité d'accueil."

3 L'Extraordinaire Voyage du fakir qui était resté coincé dans une armoire Ikea est une fable qui renferme de multiples enseignements, sur les politiques des États en matière migratoire, sur l'égoïsme contemporain, sur les aliénations consuméristes, sur les migrants clandestins, ces entrepreneurs et seuls aventuriers du siècle qui jouent leur vie pour accomplir une "mission" - "chercher du travail et envoyer de l'argent à leurs familles" -, mission si impérieuse que même l'amour ne doit pas les en détourner. Si ce premier roman connaît un tel succès, ce n'est pas seulement parce que Romain Puértolas y fait montre de brio pour embarquer son lecteur dans ces aventures abracadabrantesques, ou parce que la langue et le ton y sont enjoués, subtils, avenants, c'est aussi parce ce roman invite, dévoile, suggère - tout ici relève de la joyeuse suggestion - une autre façon de (mieux) vivre ensemble; de l'infiniment petit de nos relations interindividuelles à l'infiniment grand de l'échelle planétaire. 